distinct from one another. Specimens from the neighbourhood of the rent presented fibres with the striation in some absent, in others indistinct, all containing more or less fatty granules, the fibres themselves being much less distinct than in the more healthy specimens. Specimens from the whitish tissue of the apex, teazed with difficulty, presented no trace of muscular fibre, and consisted of fine white fibrous tissue with here and there fatty granules.

REMARKS. - This case then is a well marked example of five different pathological cardiac conditions, without any history of heart trouble till the day of death : $\mathbf{I}$. Atheroma of aorta, aortic valves, and coronary arteries; 2. Chronic myocarditis; 3. Chronic endocarditis ; 4. Fatty degeneration, probably the result of the diseased coronary arteiies; 5. Rupture of the left ventricle.

Living an easy life, in charge of an opium receiving ship, having no stairs to climb, no hill or even incline within thirty miles of Shanghai, it is probable that the patient's heart had never been severely tried. I may add that he told me he had had "a good stool the first thing in the morning as usual "; but whether this was before or after the onset of the pain, I neglected to inquire.

The microscopic specimens were mounted in Farrant's solution, and, on examination a week later, had almost ceased to be distinctive of fatty degeneration, having been perfect demonstrations when freshly put up. I understand that there is no known method of preserving the microscopic appearance of this change.

\section{NOTES ON INTERMITTENT BREATHING.}

\section{By S. WILSON HOPE, L.R.C.P., Petworth.}

IN the following notes, intermittent breathing is considered $(a)$ as coexistent with senile bronchitis, $(b)$ with hysteria, $(c)$ with inhalation of anæsthetics, (ci) with cardiac dropsy, and in view of its clinical importance-hardly second to that of intermittent heart. Some inquiry is made into its causation.

$a$. There is a lean old lady, upwards of eighty years old, whose pulse has rarely been regular any time when $I$ have felt it during the past seven years, who caught a cold; and a bad cough, with spitting of a good deal of frothy, and later of sticky, mucus, came on, and great weakness. Before the attack, she used to spend her nights sitting more or less propped up in bed, till sleep overcame her, when she usually fell over to one side, lying sleeping with the head quite low. During the early part of her illness, her nights were very restless, as were the days too; but later, for many hours during the day, through many days and weeks, she lay, taking but little notice of anything or anybody, though showing at intervals by a remark that her mind was quite clear for the moment. Very early in her illness, her niece, who nursed her, had to remove the phlegm from her mouth when she coughed; medicine had to be given up, and threatening bed-sores to be treated by a water-bed. Soon the breathing became labouring and still by turns, rhythmically; the pauses, or quasi-pauses, growing so long, that once or twice her nurse thought she had ceased to live and then food of all sorts began to be avoided, and death calmly awaited, indeed desired by her. So day after day passed, till at last a turn for the better took place; and now, though she is too weak to walk alone, her mind is as active as ever, and her breathing and pulse as before her illness.

In the same way, an old man of eighty-four or five had an illness marked in part by this peculiar intermittent breathing, which ended in recovery of his usual health; though he, too, had a very irregular and intermittent heart.

b. Many women and some men are occasionally seized in some way that they fall usually backwards, when, if watched, it will be seen that for a time the breathing is stopped, and there is quiet of muscles generally; then a period of struggling follows; then a deep drawn sigh, or several, along with incoherent talking, crying, etc.; and then either the person goes on breathing better till respiration is natural, and health is regained; or, more commonly, another pause occurs in the breathing, and a fresh attack often runs through a similar course. If we almost anticipate the pause in the breathing, and excite an inspiration, as by pouring or dashing cold water on the face just at the right time, we may often cut short an attack of this kind.

c. Again, it is curious to mark how closely this kind of fit mocks the early effects of inhaling chloroform or ether: there are the pauses, sometimes even fatal; the strugglings, and the incoherent talking, crying, etc. But the best of this class of cases is, that it seems to suggest a good working hypothesis for the whole, viz., that direct irritation of the terminal fibres of the superior laryngeal nerve is the cause of the temporary or permanent stoppage of the breathing during the inhalation of anæsthetics. But of this presently. d. We often find cases of cardiac dropsy marked by this rhythmical succession of breath-pause and breath-struggle. On watching, it is seen that the first breath drawn is followed by a rising series, in which each breathing is deeper than the foregoing till a deepest is reached; then come a falling series of shallower and shallower breathings, till the respiratory movements cease for a while. These cases, too, end sometimes in the dropsy disappearing, and the patient's getting about again.

Now, with respect to the causation of intermittent breathing, it seems to me obscure, and in want of experiments; but, adopting the method of exclusion, we find, first, that it is not caused by the cardiac disturbance, though often associated with it, because an intermittent and irregular heart is often seen in trifling cases of indigestion, where the breathing is natural; and conversely, the pulse may be steady and regular, as in some cases of apoplexy, which become marked by pauses in the breathing, though never, so far as I know, of the same peculiar rhythm. Nevertheless, they go to show that no causal connection exists between the heart and breathing troubles.

Secondly, the pauses are clearly not instances of true apnœa, that is, in which for a time the blood is saturated with oxygen; as we have only to look at the lips of our patients to see that such an idea is absurd.

Thirdly, it døes not seem to run with ordinary notions that this peculiar respiration, made up of pauses and hard breathings following each other in regular order, could be a sign of some organic change in the respiratory centre; inasmuch as such fundamental things as respiratory cardiac and vaso-motor centres, though thought liable to be stopped somehow at death, seem in themselves to be treated as above disease, just as they transcend in their effects common notions of matter and organisation.

Fourthly, it is not easy to hit upon a scheme of reflex nerve-action which will account for this breathing. Hering's experiments, showing that distending the lung with air excites fibres in the vagi, which so act on the respiratory centre as to stop respiration, hardly helps us to explain the pauses, much less their rhythm; because, though truly the hard breathings fill the lungs with air, they do not overfill them as in Hering's experiments.

Fifthly, the canon "that the activity of the respiratory movements varies inversely as their oxidating effect on the blood" does not enable us to see our way through the rhythmic hard breathings.

Enough has been said to show that the subject is obscure, and I shall be glad if this paper should lead someone to let in a little more light upon it.

\section{A CASE OF ADDISON'S DISEASE, ASSOCIATED WITH TUBERCULOSIS OF THE LUNGS AND KIDNEY.}

By HERBERT E. WRIGHT, M.R.C.S., L.R.C.P., etc.

Henry C. B., aged 8, came under my care on April 17 th, I880. His father and mother were quite healthy; there were also six brothers and sisters in good health. His mother's family were remarkably phthisical -her mother, sisters, brothers, and one or two uncles having died of phthisis.

The patient had enjoyed good health up to three years ago, when he began to suffer from cough, night sweats, and loss of flesh, for which he was treated in Liverpool for about nine months, with little benefit. About two years ago, he began to suffer from pain in his right loin; shortly after a swelling appeared at this spot. This gradyally increased in size, and became painful; on account of which the patient was taken to another medical man, who ordered the swelling to be poulticed, which was continued for three months, when the swelling burst, and discharged a considerable quantity of pus through four openings. Three of these sinuses healed up after about two months, but the fourth never healed completely, but still continued to discharge pus. The patient now began to improve considerably ; his appetite returned; he regained flesh ; and, with the exception of a slight cough and expectoration, he appeared to be quite well. His mother told me that the boy continued to improve in health until six weeks before he came under my charge, when he accidentally received a kick in his right loin, which reopened the sinuses, and caused them to discharge pus freely again. His urine at this time was thick, and offensive. His cough now became more troublesome, and he rapidly began to lose flesh. He never spat blood, but he had occasional attacks of diarrhœea.

When I saw the patient on April I7th, I880, he was extremely ema. ciated, and very tubercular-looking. I noticed about a dozen small pigment-spots scattered over the face, which, the mother informed me, had made their appearance during the last three months. The skin of the face was not much darkened; but the neck, the backs of both hands 
and wrists, and the ankles, were distinctly bronzed, though not to a very great extent. The discoloration presented no definite boundary, but gradually faded into the healthy skin. The areolæ of the nipples and the garter-lines were not materially darkened in colour. There were two sinuses, discharging thick caseous pus, immediately above the right twelfth rib. Bronchial breathing, with moist sounds and bronchophony, was heard at both apices, with some dulness on percussion. The urine was very much like that met with in chyluria, being of a milky colour, and sweetish slightly ammoniacal smell, but was loaded with pus. I considered the case to be one of Addison's disease, with scrofulous kidney discharging through the loin. The physical examination also clearly showed the coexistence of phthisis. The patient was ordered to take a teaspoonful of syrup of iodide of iron, with a like quantity of vinum ferri, three times a day; while carbolic dressings were applied to the sinuses in the loins. He gradually grew weaker, and the sinuses continued to discharge large thick masses of pus, sometimes as large as the finger of an adult. He died of asthenia on July 2nd, I88o.

On July 3 rd, I made a post mortem examination, but I was allowed by the friends of the patient to open the abdomen only, so that I am sorry I was not able to confirm the diagnosis of phthisis; but I feel confident, from the physical examination, that phthisis did exist. The body was exceedingly emaciated. There were two large sinuses in the right lumbar region, about the position of the kidney, through which a long piece of caseous matter, about the size of one's finger, projected. The skin of the neck, ankles, back of the hands, and wrists, was of a distinctly brownish colour ; the nipples also were pigmented. The left kidney was healthy, but considerably hypertrophied. The left suprarenal capsule appeared to be quite healthy. The right kidney was totally destroyed, and converted into a large irregular caseous abscess, which communicated freely with the sinuses in the loin. The abscess extended upwards to the back of the right lobe of the liver, forming a cavity in that viscus about the size of an orange. The right suprarenal capsule was found intimately adherent to the upper and front wall of the abscess; it was of irregular outline, enlarged, and in section presented numerous cavities formed by broken-down caseous tubercle; in other parts, the structure was more fibrous and firmer. The liver and spleen were enlarged, and distinctly lardaceous.

REMARKS. - The above case seems to me to present several points of interest. It is very rare to find this disease affecting so young a patient. I remember seeing a girl, aged I6, who was the subject of Addison's disease, when I was clinical assistant at Guy's Hospital ; but I have never heard of its occurring in so young a patient as the one $I$ have just recorded. Again : both capsules are usually aftected; but in this case the left appeared to be quite healthy, and this may be the explanation of the bronzing being only slightly marked. The hypertrophy of the left kidney was, of course, compensatory to the destruction of the right. One would like to know, if it were possible, which was the primary seat of the tubercle-whether the lung, kidney, or capsule; my own impression is that the capsule was involved secondarily to, and as an extension from, the kidney.

CANCER OF THE THIGH REMOVED PAINLESSLY, WITHOUT CHLOROFORM OR ETHER-SPRAY.

\section{By JOHN F. LE PAGE, L.R.C.P.Ed., Durham.}

J. J., AGED forty-three years, consulted me, on January Ioth, 1879 , respecting a tumour of his right thigh. On examination, I found a scirrhus, of the size of a small orange, on the anterior aspect. Ulceration had commenced several weeks previously, and extended over a surface measuring five and a half inches in circumference. It would appear that the nature of the tumour had not been clearly comprehended, for it had been poulticed for three or four weeks. Very extreme pain at times was complained of. I urged the importance of an early removal of the cancer; and, my patient being willing to submit to any mode of operating considered most advisable, I decided, having before had very good results from similar treatment, to destroy the malignant growth previous to its removal. And I did so, not withstanding the opinion of many surgeons of considerable experience to the contrary, in the belief that some caustics exercise a specific action on the morbid structures of cancer; and that thus their action extends somewhat into surrounding tissues, infiltrated with cancer-cells or plasma, which are thus rendered at least unproductive, whilst the tissues themselves are not disorganised.

Although local anarsthesia was not used in the operation, I used, shortly before it, Richardson's ether-spray producer over the margins of the ulcerating surface, for a distance of about an inch from the edge. Pure nitric acid was then applied to the skin, destroying it for the breadth of half an inch all round. This preparation was neces- sary, as chloride of zinc, which was to be used, acts very slowly on organised skin.

The cancer was situated about two inches below the point where the middle cutaneous nerve pierces the fascia lata. Immediately above the new margin, I injected five-eighths of a grain of morphia with a long subcutaneous needle. One part of chloride of zinc was then mixed into a paste, with two parts of flour and a little water, and thickly plastered over the whole surface. After six hours, the caustic was removed, and poultices applied. On the seventh day the eschar separated, and careful inspection with a lens revealed, between the healthy granulations, on all sides débris, which, on microscopic examination, was found to contain cancer-cells. I decided to again apply the chloride; and, after injecting morphia as before, plastered the caustic freely over the surfaces, continuing the application for three hours. Poultices were again applied, and, on the fifth day, the eschar was easily removed. After sponging the cavity, the beautiful glistening fascia lata was seen quite clean at the bottom, whilst the sides were covered with perfectly healthy granulations. A carbolic acid lotion was used, and the cavity rapidly filled up. In eight weeks, the healing process was completed. On December 2nd, 1881, my patient called on me, that I might see that the cure was altogether radical. In every respect, the leg is practically as good as its fellow, and there is abundant evidence that every vestige of the malignant growth was removed.

My object in recording this case is, not so much to laud the use of escharotics-although, without doubt, in many cases of malignant disease, they are very far superior to the knife-but to note the advantages of the mode of operating which I adopted. The great drawback to the use of caustics is, of course, the intense and protracted torture they inflict, for hours and even days-a torture to which the "stoutest heart" can hardly submit. In this case, the chloride of zinc was twice applied, in all for nine hours; and, neither during that period, nor subse quently, was any pain whatever experienced. My patient conversed freely during the hour I remained with him after the first application of the chloride; and on my returning, five hours later, he told me that he had thoroughly enjoyed a substantial dinner, and had smoked a cigar. This great desideratum, the immunity from pain, was attained by temporarily abrogating, through the direct application of morphia, the power to transmit centripetal impulses of the middle, and perhaps also of a branch of the external cutaneous nerve.

\section{SURGICAL MEMORANDA.}

\section{EARLY EXCISION OF THE KNEE-JOINT.}

With reference to Professor Stokes's paper in the BRITISH MEDICAI JOURNAL of December Ioth, it appears to me that much of the existing difference of opinion regarding the propriety of excising the knee-joint arises from the varying conditions under which our patients exist. In Loncion, surgeons at the present time have almost unlimited opportunities for sending hospital patients to convalescent homes in the country. Many of these establishments are admirably managed, and situated in healthy seaside localities. Under these circumstances, the children of our poor suffering from the early stage of joint-disease have all the advantages enjoyed by their more wealthy neighbours. Most of these patients may be cured without excision of the affected joint.

For instance, some days ago, when going round the Westminster Hospital, two patients (one a boy aged I I, and the other a girl aged 9) came to visit me on their return from a residence respectively of nine and seven months in convalescent homes. Both patients had been under my care for pulpy degeneration or granular synovitis of the right knee-joint; and, in addition, the boy's hip-joint was similarly affected. His was almost as unpromising a case as it was possible to meet with; but he has returned a healthy lad, full of vigour, and with joints that will stand many a long day's work.

I cannot comprehend the necessity that exists for excising a slice from the ends of the bones in the early stages of pulpy degeneration of the knee, because the disease (unlike tuberculous ostitis) commences, as a rule, in the synovial membrane, the bones being subsequently im. plicated. It is true, after removing the ends of the bones, we can get them to grow together, and so do away with the necessity for a synovial membrane. Nor can I understand the objection so strongly urged by Professor Stokes against the plan of treating these cases by incision and drainage, because of the danger incurred by suppuration. The treatment by incision and drainage can be carried out antiseptically, with results, so far as inflammation is concerned, as favourable as that attending his practice after resection of the joint. Before, how. ever, disease of the knee has reached the stage when some surgeons advocate treatment by incision and drainage, Professor Stokes 